\title{
Predictive Control for Active Split DC-bus 4-leg Inverters
}

\author{
S. Bifaretti, S. Pipolo \\ Dept. of Industrial Engineering \\ University of Rome Tor Vergata \\ C-PED, Center for Power Electronics \\ and Drives \\ Rome, Italy \\ bifaretti@ing.uniroma2.it
}

\author{
A. Lidozzi, L. Solero \\ Dept. of Engineering \\ Roma Tre University \\ C-PED, Center for Power Electronics \\ and Drives \\ Rome, Italy \\ alessandro.lidozzi@uniroma3.it
}

\author{
L. Tarisciotti, P. Zanchetta \\ Dep. of Electrical and Electronic \\ Engineering \\ University of Nottingham, \\ Nottingham, U.K. \\ Luca.Tarisciotti@nottingham.ac.uk
}

\begin{abstract}
This paper proposes a Predictive Control, formally Dead-Beat (DBC), for a four-leg inverter having an Active Split DC-bus on the fourth leg and LC filters on phase-to-neutral outputs. Such a configuration permits to reduce the voltage ripple on the neutral point connected to inverter grounding. As only few control techniques have been investigated for Active Split DC-bus, the paper proposes to investigate the performance of $\mathrm{DBC}$, which has been widely used for other power electronics applications. The main advantage of DBC over the classical PI or Resonant controller is that no tuning is required for control loop, while obtaining very fast transient response as well it can handle general constrained nonlinear systems with multiple inputs and outputs in a unified and clear manner. These features are highly valuable in power electronic converters used to supply the electrical utility loads in micro-grids. However, one of the main drawback of the DBC is the limited capabilities on harmonics compensations required when supplying unbalanced and non-linear loads. The paper presents continuous-time and discrete-time models of DBC applied to a four-leg VSI with Active Split DC-bus, highlighting the performance through simulation results as well as experimental tests.
\end{abstract}

\section{INTRODUCTION}

Voltage Source Inverter (VSI) topology is finding increasing utilization in the supply of electrical utility systems due to the widespread use of UPS and active filtering units, for an improved quality of the energy supply, as well as in the growing use of renewable energy resources in distributed generating systems. These may be arranged in form of micro-grid with common DC-bus, as schematically depicted in Fig. 1. In such applications, the output inverter is used to supply the electrical utility loads, which can be either single or three phase loads and, in the case of three-phase loads, they can be either balanced or unbalanced. Hence, a four-wire electrical distribution system must be arranged for the supply of such utility loads and to this goal, a stable and ripple-free neutral connection must be provided, in order to avoid recirculation of currents through the system stray capacitances, in particular when the TT grounding arrangement is used.

In the case of the four-leg VSI topology several configurations are offered, one approach relies on simply adding a fourth leg in the conventional VSI layout so that the middle point of such switching leg is directly used as the inverter $\mathrm{N}$ terminal. Alternatively, a filtering inductor is placed between the output $\mathrm{N}$ terminal and the active phase-leg. Such an arrangement allows that the neutral wire is stabilized with respect to the fundamental frequency, but a significant voltage ripple still affects the waveform of the voltages measured between the $\mathrm{N}$ point and the DC-plus and DCminus bars. The high frequency oscillations occur at the switching frequency and its related multiple values, so that issues may arise concerning the grounding arrangement (i.e. TT or TN) adopted for the utility system. When TN arrangement is used, this leads to recirculating currents on the DC-Link side system, in particular through large surface PV units; instead, when TT system is used, high common mode voltage arises at the load-side, leading to possible malfunctions of enduser equipment.

A different arrangement of the fourth-leg can be used to provide a ripple free $\mathrm{N}$-wire at both the fundamental and switching frequencies [1]. Such a novel configuration is the combination of the previously described topologies and leads to the so-called Active Split DC-bus configuration, as shown in Fig. 2, which is the four-terminal VSI topology. This technical contribution refers to the inverter output filter configuration as illustrated in Fig. 3, which is suggested in both stand-alone and grid-tied applications [2]. Behind the main LC filter, a switching trap tuned at the inverter switching frequency and a selective dumper have been inserted between each phase and the common neutral connection. Such a system imposes to use a constant switching frequency, otherwise the filtering benefits can be strongly reduced. Classical Control structures, based on PI or Resonant (RC) regulators, have the benefit of an easy implementation and, especially in case of $\mathrm{RC}$, fast transient response and high performance in assuring low harmonic content at the inverter outputs; however, their tuning is not straightforward and, if not accurately designed, can lead to stability issues. Model Predictive Control can produce good performance, but it exhibits an upper limited switching frequency [3]-[8], resulting in a varying commutation frequency, which is highly not indicated in case of specifically tuned filters. Moreover, large output filters have to be used in order to comply with international grid codes [9]. Solutions to keep a constant switching frequency have been proposed in [10], [11] with the so-called Modulated Model Predictive Control (M2PC) which can be useful employed in case of multiobjective control strategies. The paper focuses on the detailed description of continuous-time and discretetime models of DBC applied to four-leg VSIs with Active Split DC-bus. The performance of the proposed 
strategy are evaluated through an accurate simulation model and then validated by experimental tests.

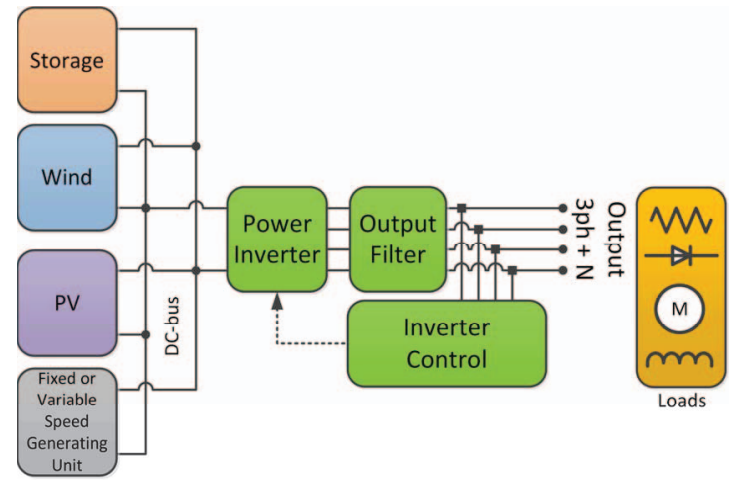

Fig. 1. Typical application of the front-end inverter.

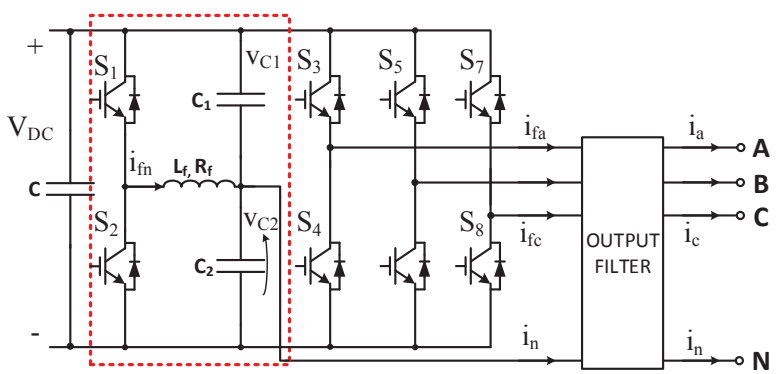

Fig. 2. VSI 4-leg topology with Active Split DC-bus.

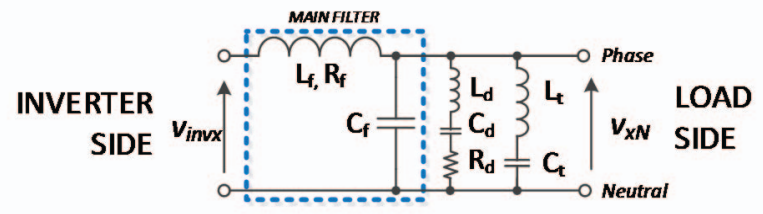

Fig. 3. Phase-to-neutral scheme of output power filter.

\section{SYSTEM MODEL}

The VSI Inverter model can be described by the following differential equations:

$$
\begin{gathered}
\frac{d i_{f x}(t)}{d t}=\frac{1}{L_{f}}\left[-R_{f} i_{f x}(t)+v_{i n v x}(t)-v_{x N}(t)\right]= \\
=\frac{1}{L_{f}}\left[-R_{f} i_{f x}(t)+S_{1 x} v_{C 1}(t)-S_{2 x} v_{C 2}(t)-v_{x N}(t)\right] \\
\frac{d v_{x N}(t)}{d t}=\frac{1}{C_{x}}\left[i_{f x}(t)-i_{x}(t)\right]
\end{gathered}
$$

being $x=a, b, c$ one of the three inverter phases, $i_{f x}$ the filter current, $R_{f}$ the parasitic resistance of filter inductor, $v_{i n v x}$, the inverter Phase-to-Neutral voltage, $v_{x N}$ the phaseto-Neutral output voltage, $S_{l x}$ and $S_{2 x}$ the switching functions, for the upper and lower leg switches respectively. The switching functions assume a value equal to 1 , when the corresponding switch is closed, or equal to 0 in the opposite case.
The DC-link Voltage, assumed as a constant and the neutral current $i_{n}$ are subject to the following constrains:

$$
\begin{gathered}
V_{D C}=v_{C 1}(t)+v_{C 2}(t) \\
i_{n}(t)=-\left(i_{a}(t)+i_{b}(t)+i_{c}(t)\right)
\end{gathered}
$$

Using the same approach as for Inverter model, the neutral leg $n$ with Active Split DC-bus model can be described by defining the differential equations:

$$
\begin{gathered}
\frac{d i_{f n}(t)}{d t}=\frac{1}{L_{f}}\left[-R_{f} i_{f n}(t)+S_{1 n} v_{C 1}(t)-S_{2 n} v_{C 2}(t)\right] \\
\frac{d v_{c 2}(t)}{d t}=\frac{1}{C_{1}+C_{2}}\left[i_{f n}(t)-i_{n}(t)\right]
\end{gathered}
$$

$$
\text { being } \frac{d v_{c 1}(t)}{d t}=-\frac{d v_{c 2}(t)}{d t} \text { from }(2) \text {. }
$$

In order to permit a separate control of the fourth leg and, as a consequence, reduce the computational complexity, an equivalent model in fixed reference frame $(\alpha, \beta)$ is considered. Using the Clarke's transformations in (5) and (6), the equivalent $(\alpha, \beta)$ models shown in Fig. 4 , being $x$ the inverter voltage or the filter current, the equivalent $(\alpha, \beta)$ models shown in Fig. 4 , are obtained.

$$
\begin{aligned}
& x_{\alpha}=\frac{2}{3}\left[x_{a}-\left(x_{b}+x_{c}\right)\right] \\
& x_{\beta}=\frac{\sqrt{3}}{3}\left(x_{b}+x_{c}\right)
\end{aligned}
$$
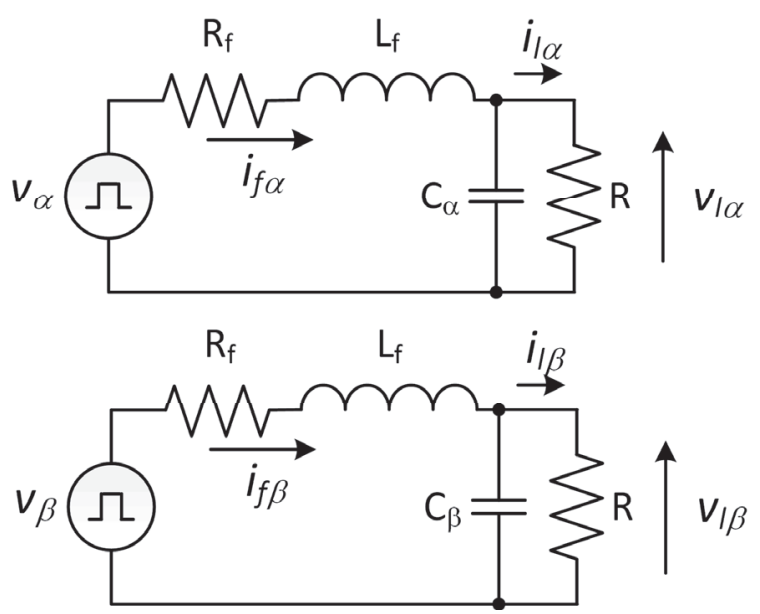

Fig. 4. Equivalent $(\alpha, \beta)$ circuits.

The voltages produced by the VSI are related to the switching states and the DC-Link voltage $V_{D C}$ according to the following equations:

$$
\begin{aligned}
& v_{c \alpha}(t)=S_{\alpha}(t) V_{D C} \\
& v_{c \beta}(t)=S_{\beta}(t) V_{D C}
\end{aligned}
$$

Consequently, the VSI can produce on the $(\alpha, \beta)$ plane, six active vectors and two zero vectors. $S_{\alpha}$ and $S_{\beta}$ represent the normalized amplitude of voltage vectors components related to the switching configurations, as shown in Table I. 
TABLE I. SWITCHING STATES AND EQUIVALENT $(\alpha, \beta)$ COMPONENTS

\begin{tabular}{cccccc}
\hline \hline $\mathrm{S}$ & $\mathrm{S}_{1} / \mathrm{S}_{2}$ & $\mathrm{~S}_{3} / \mathrm{S}_{4}$ & $\mathrm{~S}_{5} / \mathrm{S}_{6}$ & $\mathrm{~S}_{\alpha}$ & $\mathrm{S}_{\beta}$ \\
\hline 0 & $0 / 1$ & $0 / 1$ & $0 / 1$ & 0 & 0 \\
1 & $1 / 0$ & $0 / 1$ & $0 / 1$ & $2 / 3$ & 0 \\
2 & $1 / 0$ & $1 / 0$ & $0 / 1$ & $1 / 3$ & $\sqrt{ } 3 / 3$ \\
3 & $0 / 1$ & $1 / 0$ & $0 / 1$ & $-1 / 3$ & $\sqrt{ } 3 / 3$ \\
4 & $0 / 1$ & $1 / 0$ & $1 / 0$ & $-2 / 3$ & 0 \\
5 & $0 / 1$ & $0 / 1$ & $1 / 0$ & $-1 / 3$ & $-\sqrt{ } 3 / 3$ \\
6 & $1 / 0$ & $0 / 1$ & $1 / 0$ & $1 / 3$ & $-\sqrt{ } 3 / 3$ \\
7 & $1 / 0$ & $1 / 0$ & $1 / 0$ & 0 & 0 \\
\hline \hline
\end{tabular}

According to the $(\alpha, \beta)$ representation shown in Fig. 4 , the following continuous-time model can be written:

$$
\left\{\begin{array}{c}
\frac{d i_{f \alpha}(t)}{d t}=\frac{1}{L_{f}}\left[v_{i n v \alpha}(t)-v_{l \alpha}(t)\right]-\frac{R_{f}}{L_{f}} i_{f \alpha}(t) \\
\frac{d i_{f \beta}(t)}{d t}=\frac{1}{L_{f}}\left[v_{i n v \beta}(t)-v_{l \beta}(t)\right]-\frac{R_{f}}{L_{f}} i_{f \beta}(t) \\
\frac{d v_{l \alpha}(t)}{d t}=\frac{1}{C_{f}}\left[i_{f \alpha}(t)-i_{l \alpha}(t)\right] \\
\frac{d v_{l \beta}(t)}{d t}=\frac{1}{C_{f}}\left[i_{f \beta}(t)-i_{l \beta}(t)\right]
\end{array}\right.
$$

A discrete-time model is achieved from (9) assuming that the system variables are constant during the sampling interval $T_{s}$.

$$
\left\{\begin{array}{c}
i_{f \alpha}\left(t_{k}+T_{s}\right)=K_{1} i_{f \alpha}\left(t_{k}\right)+K_{2}\left[v_{i n v \alpha}\left(t_{k}\right)-v_{l \alpha}\left(t_{k}\right)\right] \\
i_{f \beta}\left(t_{k}+T_{s}\right)=K_{1} i_{f \alpha}\left(t_{k}\right)+K_{2}\left[v_{i n v \beta}\left(t_{k}\right)-v_{l \beta}\left(t_{k}\right)\right] \\
v_{l \alpha}\left(t_{k}+T_{s}\right)=v_{l \alpha}\left(t_{k}\right)+K_{3}\left[i_{f \alpha}\left(t_{k}\right)-i_{l \alpha}\left(t_{k}\right)\right] \\
v_{l \beta}\left(t_{k}+T_{s}\right)=v_{l \beta}\left(t_{k}\right)+K_{3}\left[i_{f \beta}\left(t_{k}\right)-i_{l \beta}\left(t_{k}\right)\right]
\end{array}\right.
$$

where $t_{k}$ is the actual sampling instant, $v_{\text {inv } \alpha}$ and $v_{\text {inv } \beta}$ are the average voltage components produced by the converter calculated in the previous sampling time, and $K_{1}, K_{2}$ are two constants defined as:

$$
\begin{gathered}
K_{1}=e^{-\frac{R_{f}}{L_{f}} T_{s}} \approx 1-\frac{R_{f}}{L_{f}} T_{s} \\
K_{2}=\frac{1}{R_{f}}\left(1-e^{-\frac{R_{f}}{L_{f}} T_{s}}\right) \approx \frac{T_{s}}{L_{f}} \\
K_{3}=\frac{T_{s}}{C_{f}}
\end{gathered}
$$

\section{PROPOSED PREDICTIVE CONTROL}

Fig. 5 shows the block scheme of the proposed Predictive Controller for the 4-leg Active Split DC bus VSI. The control strategy aim to perform separate control between the three-phase VSI and the fourth leg avoiding complex modulation strategies [12]. In order to obtain a constant switching frequency required for an effective output filtering, a predictive dead-beat control strategy has been chosen for the VSI.
Dead-Beat control [13], [14] is a model-based strategy which performs, at every sampling interval, the prediction of the system response to a modification in the controlled variables in order to achieve a near zero error usually in the next sampling period. In practical implementations the computational time has to be compensated, to avoid affecting the control action, with one sampling interval delay. To compensate for such a delay, the two step prediction proposed in [15] is used.

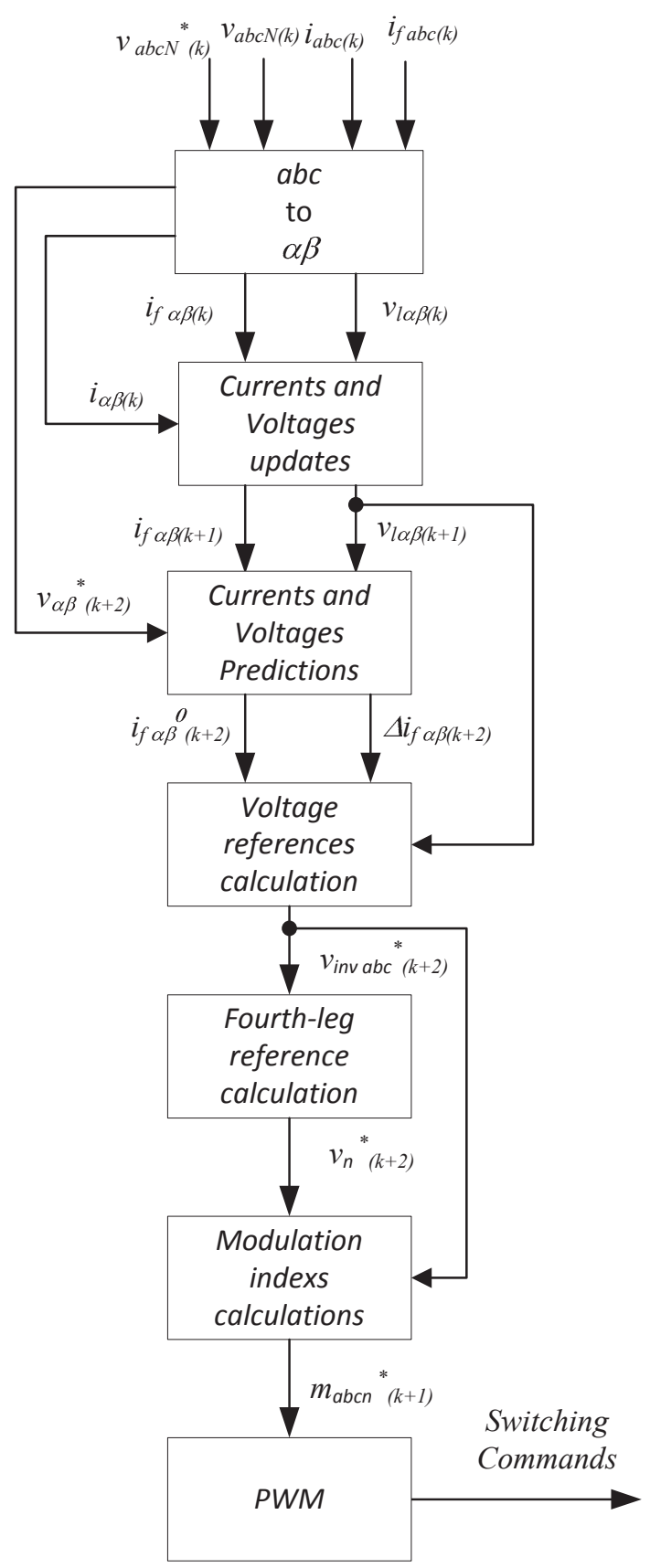

Fig. 5. Block diagram of the proposed controller.

The determination of the output reference voltages $v_{\text {invxabc }}{ }^{*}\left(t_{k}+2 T_{s}\right)$ is achieved based on the contributions of the free and forced evolution.

The currents predictions (10) can be written as:

$$
\begin{aligned}
& i_{f \alpha}\left(t_{k}+2 T_{s}\right)=i_{f \alpha}{ }^{0}\left(t_{k}+2 T_{s}\right)+K_{2} V_{i n v \alpha}\left(t_{k}+T_{s}\right) \\
& i_{f \beta}\left(t_{k}+2 T_{s}\right)=i_{f \beta}{ }^{0}\left(t_{k}+2 T_{s}\right)+K_{2} V_{i n v \beta}\left(t_{k}+T_{s}\right)
\end{aligned}
$$


where $i_{\alpha}{ }^{0}, i_{\beta}{ }^{0}$ are the contributions of the free evolution of output filter current:

$$
\begin{aligned}
& i_{f \alpha}{ }^{0}\left(t_{k}+2 T_{s}\right)=K_{1} i_{f \alpha}\left(t_{k}+T_{s}\right)-K_{2} v_{l \alpha}\left(t_{k}\right) \\
& i_{f \beta}{ }^{0}\left(t_{k}+2 T_{s}\right)=K_{1} i_{f \alpha}\left(t_{k}+T_{s}\right)-K_{2} v_{l \beta}\left(t_{k}\right)
\end{aligned}
$$

The contribution of forced evolution can be achieved by computing, for each component, the amount of current that shall flow in the inductor filter to reach the desired references $i_{f \alpha}{ }^{*}\left(t_{k}+2 T_{s}\right), i_{f \beta}{ }^{*}\left(t_{k}+2 T_{s}\right)$.

The current errors $\Delta i_{f \alpha}{ }^{*}\left(t_{k}+2 T_{s}\right), \Delta i_{f \beta}{ }^{*}\left(t_{k}+2 T_{s}\right)$ are calculated as the difference between the current references and the currents produced from the zero vectors:

$$
\begin{aligned}
& \Delta i_{f \alpha}\left(t_{k}+2 T_{s}\right)=i_{f \alpha}{ }^{*}\left(t_{k}+2 T_{s}\right)-i_{f \alpha}{ }^{0}\left(t_{k}+2 T_{s}\right) \\
& \Delta i_{f \beta}\left(t_{k}+2 T_{s}\right)=i_{f \beta}{ }^{*}\left(t_{k}+2 T_{s}\right)-i_{f \beta}{ }^{0}\left(t_{k}+2 T_{s}\right)
\end{aligned}
$$

Considering the control working properly is possible to assume:

$$
\left\{\begin{array}{l}
i_{f \alpha}\left(t_{k}+2 T_{s}\right)=i_{f \alpha}{ }^{*}\left(t_{k}+2 T_{s}\right) \\
i_{f \beta}\left(t_{k}+2 T_{s}\right)=i_{f \beta}{ }^{*}\left(t_{k}+2 T_{s}\right) \\
v_{l \alpha}\left(t_{k}+2 T_{s}\right)=v_{l \alpha}{ }^{*}\left(t_{k}+2 T_{s}\right) \\
v_{l \beta}\left(t_{k}+2 T_{s}\right)=v_{l \beta}{ }^{*}\left(t_{k}+2 T_{s}\right)
\end{array}\right.
$$

Therefore, the current references are computed by inverting the $3^{\text {rd }}$ the $4^{\text {th }}$ of $(10)$ together with assumptions (11):

$$
\begin{aligned}
& i_{f \alpha}{ }^{*}\left(t_{k}+2 T_{S}\right)=i_{l \alpha}\left(t_{k}+T_{S}\right)+\frac{v_{l \alpha}{ }^{*}\left(t_{k}+2 T_{S}\right)-v_{l \alpha}\left(t_{k}+2 T_{S}\right)}{K_{3}} \\
& i_{f \beta}{ }^{*}\left(t_{k}+2 T_{S}\right)=i_{l \beta}\left(t_{k}+T_{S}\right)+\frac{v_{l \beta}{ }^{*}\left(t_{k}+2 T_{S}\right)-v_{l \beta}\left(t_{k}+2 T_{S}\right)}{K_{3}}
\end{aligned}
$$

The converter voltage references in $(\alpha, \beta)$ reference frame are finally obtained as:

$$
\begin{aligned}
& v_{i n v \alpha}{ }^{*}\left(t_{k}+2 T_{s}\right)=v_{l \alpha}\left(t_{k}+T_{s}\right)+\frac{\Delta i_{f \alpha}\left(t_{k}+2 T_{s}\right)}{K_{2}} \\
& v_{i n v \beta}{ }^{*}\left(t_{k}+2 T_{s}\right)=v_{l \beta}\left(t_{k}+T_{s}\right)+\frac{\Delta i_{f \beta}\left(t_{k}+2 T_{s}\right)}{K_{2}}
\end{aligned}
$$

Applying the inverse Clarke's transformation to the last relations, the references for the three output voltages $v_{\text {invxa }}{ }^{*}\left(t_{k}+2 T_{s}\right), \quad v_{\text {invxb }}{ }^{*}\left(t_{k}+2 T_{s}\right), \quad v_{\text {invxc }}{ }^{*}\left(t_{k}+2 T_{s}\right) \quad$ can be achieved.

In order to maintain the benefit in terms of harmonic content of the conventional three-phase VSI feeding a star-connected balanced load, a proper zero-sequence signal $v_{n}{ }^{*}\left(t_{k}+2 T_{s}\right)$ has to be used as a reference to control the fourth-leg. The most common and effective solution, adopted in this paper, is based on the following relationship [16]:

$$
\begin{aligned}
& D_{\text {max }}=\max \left(v_{a n}^{*}, v_{b n}^{*}, v_{c n}^{*}\right) \\
& D_{\text {min }}=\min \left(v_{a n}^{*}, v_{b n}^{*}, v_{c n}^{*}\right)
\end{aligned}
$$

$$
v_{n}^{*}=-\frac{D_{\max }-D_{\min }}{2}
$$

\begin{tabular}{|c|c|c|c|}
\hline Main Filter & $L_{f}=800 \mu \mathrm{H}$ & $C_{f}=5 \mu \mathrm{F}$ & $R_{f}=50 \mathrm{~m} \Omega$ \\
\hline $\begin{array}{c}\text { Neutral } \\
\text { Filter }\end{array}$ & $L_{n}=200 \mu \mathrm{H}$ & $C_{1}=C_{2}=2.35 \mu \mathrm{F}$ & $R_{n}=10 \mathrm{~m} \Omega$ \\
\hline Trap Filter & $L_{\mathrm{t}}=187 \mu \mathrm{H}$ & $C_{t}=2 \times 0.47 \mu \mathrm{F}$ & $R_{\mathrm{t}}=20 \mathrm{~m} \Omega$ \\
\hline Damper & $L_{d}=1000 \mu \mathrm{H}$ & $C_{d}=8.1 \mu F$ & $R_{\mathrm{d}}=15 \Omega$ \\
\hline DC-link & $V_{\mathrm{dc}}=700 \mathrm{~V}$ & $C_{\mathrm{dc}}=800 \mu \mathrm{F}$ & \\
\hline Control & $T_{s}=8.33 \mu \mathrm{s}$ & $f_{s}=12 \mathrm{kHz}$ & $\begin{array}{c}\text { Time step }= \\
T_{s} / 100\end{array}$ \\
\hline
\end{tabular}

In order to use a triangular waveform for the neutral voltage $v_{n}$ with the Active Split DC-bus configuration and avoids the negative effects produced by interaction of the neutral voltage harmonics and the Active Split filter, the resonance frequency of the filter shall be selected 1 decade higher than the injected harmonic frequency, as highlighted in [17].

\section{SIMULATION AND EXPERIMENTAL RESULTS}

The proposed control strategy, has been verified, at first, by a specific simulation model developed in PLECS employing the parameters listed in Table II.

Fig. 6 shows the behavior of the converter in the case of an unbalanced 3-phase resistive load $(1 \mathrm{~kW}, 2 \mathrm{~kW}$, $2 \mathrm{~kW}$ on each of the three phases respectively) whilst, in Fig. 7, the waveforms are referred to unbalanced and non-linear load case when a single-phase diode rectifier load is applied on phase $a$. The phase-to-neutral voltages waveforms present a good harmonic content with a THD value equal to about $2 \%$ for resistive unbalanced load and to about $5 \%$ for non-linear unbalanced load, thus compliant to the limits imposed by the standard IEC 61000-3-2..

Experimental tests have been then performed on the four-leg hardware setup shown in Fig. 8, with the output power filter depicted in Fig. 9 and employing the same operating conditions as in simulation. Such results have been achieved implementing the illustrated control structure with a discretization frequency step equals to the inverter switching frequency. Output voltages behavior with linear balanced load is shown in Fig. 10 where the load is suddenly changed from no-load condition to around $2 \mathrm{~kW}$ per phase. It can be noticed the good performance even when the load is connected close to the phase voltage peak value, which represents the worst condition. Performance of the Predictive algorithm with unbalanced nonlinear loads are shown in Fig. 11 where a single-phase diode rectifier has been connected between phase $a$ and the output neutral connector. As soon as the load is fed, the output voltages waveform behavior proves the effectiveness of the Predictive strategy, being able to fast compensate for both harmonics and voltage drop. 


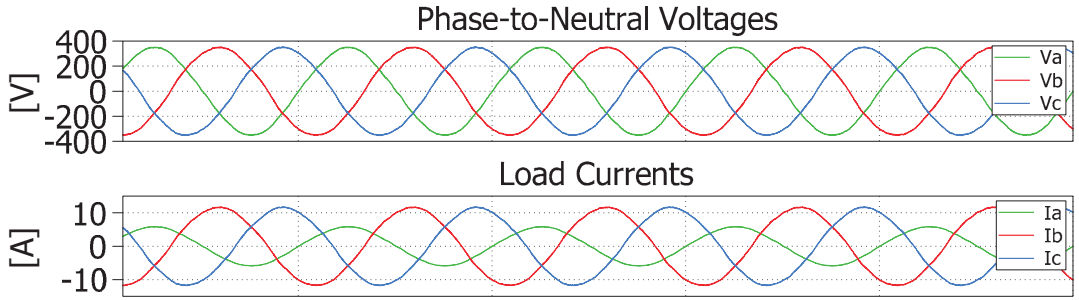

Active Split DC Voltages
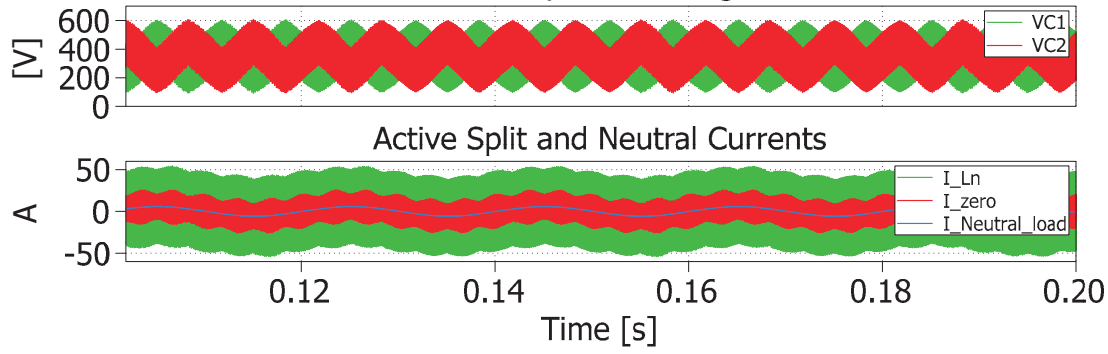

Fig. 6. Linear unbalanced load.

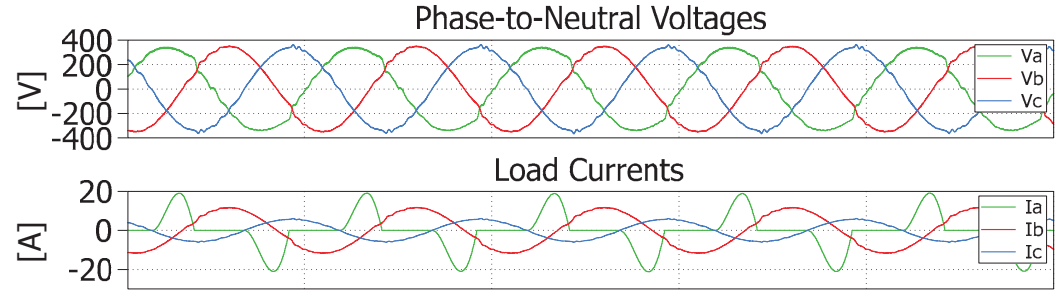

Active Split DC Voltages

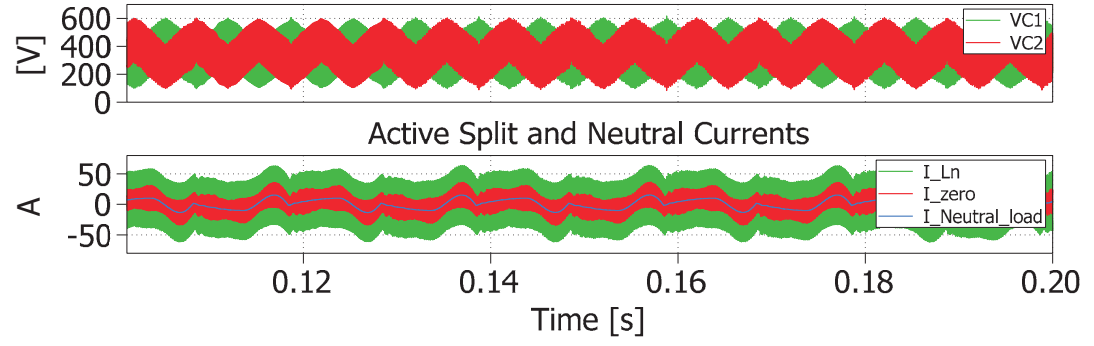

Fig. 7. Nonlinear single phase diode rectifier load.

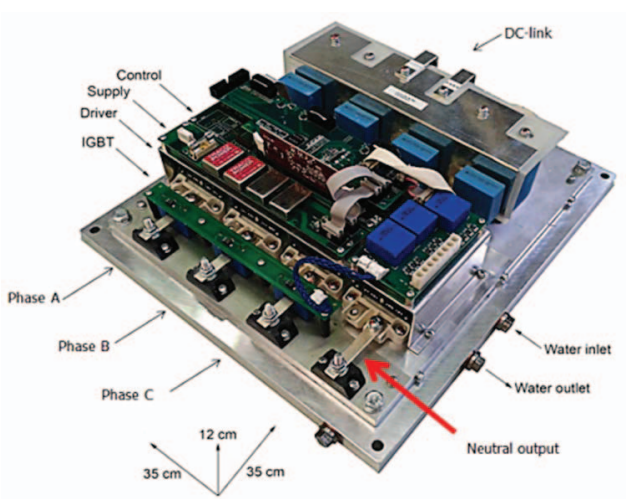

Fig. 8. Four-leg VSI converter prototype.

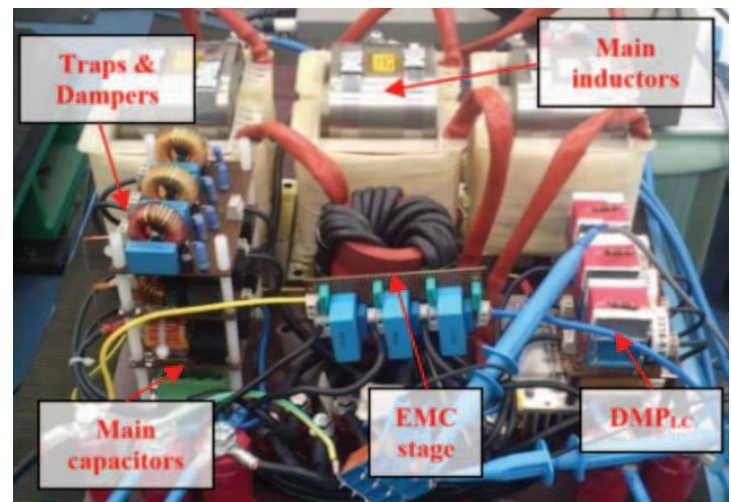

Fig. 9. Inverter output power filter. 


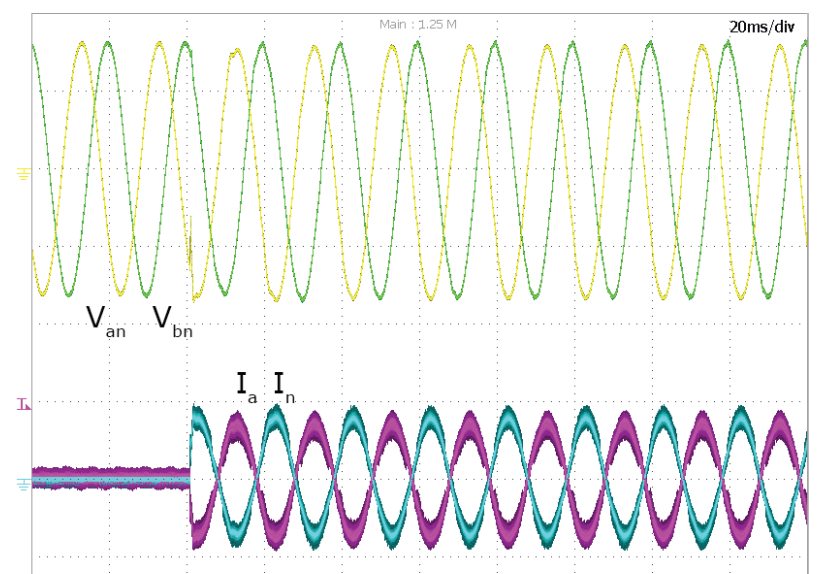

Fig. 10. Linear balanced load step. (20 A/div, $200 \mathrm{~V} / \mathrm{div})$

\section{CONCLUSIONS}

The paper investigates the application of the DeadBeat strategy to control a 4-leg VSI having an Active Split DC-bus on the fourth leg and used to supply both unbalanced and non-linear electrical utility loads in a micro-grid. A detailed description of the discrete-time model, even useful for a practical implementation on Microprocessor, has been presented. Compared to high performance Resonant Controllers, the Predictive Controller has the certain advantage to do not require any tuning of regulator gains; on the other hands, it exhibits a lower harmonic compensation capability.

\section{REFERENCES}

[1] A. Lidozzi, G. L. Calzo, S. Pipolo, L. Solero, and F. Crescimbini, "Modeling of voltage source inverter having active split DC-bus for supply of four-wire electrical utility systems," in Energy Conversion Congress and Exposition (ECCE), 2014 IEEE, 2014, pp. 1043-1050.

[2] G. Lo Calzo, A. Lidozzi, L. Solero, and F. Crescimbini, "LC Filter Design for On-Grid and Off-Grid Distributed Generating Units," IEEE Trans. Ind. Appl., vol. 51, no. 2, pp. 1639-1650, Mar. 2015.

[3] M. Rivera, V. Yaramasu, A. Llor, J. Rodriguez, B. Wu, and M. Fadel, "Digital Predictive Current Control of a Three-Phase Four-Leg Inverter," IEEE Trans. Ind. Electron., vol. 60, no. 11, pp. 4903-4912, Nov. 2013.

[4] V. Yaramasu, M. Rivera, M. Narimani, B. Wu, and J. Rodriguez, "Model Predictive Approach for a Simple and Effective Load Voltage Control of Four-Leg Inverter With an Output LC Filter," IEEE Trans. Ind. Electron., vol. 61, no. 10, pp. 5259-5270, Oct. 2014.

[5] P. Cortes, A. Wilson, S. Kouro, J. Rodriguez, and H. Abu-Rub, "Model Predictive Control of Multilevel Cascaded H-Bridge Inverters," IEEE Trans. Ind. Electron., vol. 57, no. 8, pp. 2691-2699, Aug. 2010.

[6] B. S. Riar, T. Geyer, and U. K. Madawala, "Model Predictive Direct Current Control of Modular Multilevel Converters: Modeling, Analysis, and Experimental Evaluation," IEEE Trans. Power Electron., vol. 30, no. 1, pp. 431-439, Jan. 2015.

[7] M. Preindl and S. Bolognani, "Model Predictive Direct Speed Control with Finite Control Set of PMSM Drive Systems," IEEE Trans. Power Electron., vol. 28, no. 2, pp. 1007-1015, Feb. 2013.

[8] M. Parvez Akter, S. Mekhilef, N. Mei Lin Tan, and H. Akagi, "Modified Model Predictive Control of a Bidirectional AC-DC Converter Based on Lyapunov Function for Energy Storage Systems," IEEE Trans. Ind. Electron., vol. 63, no. 2, pp. 704-715, Feb. 2016.

[9] M. Rivera, V. Yaramasu, A. Llor, J. Rodriguez, B. Wu, and M. Fadel, "Digital predictive current control of a three-phase four-leg

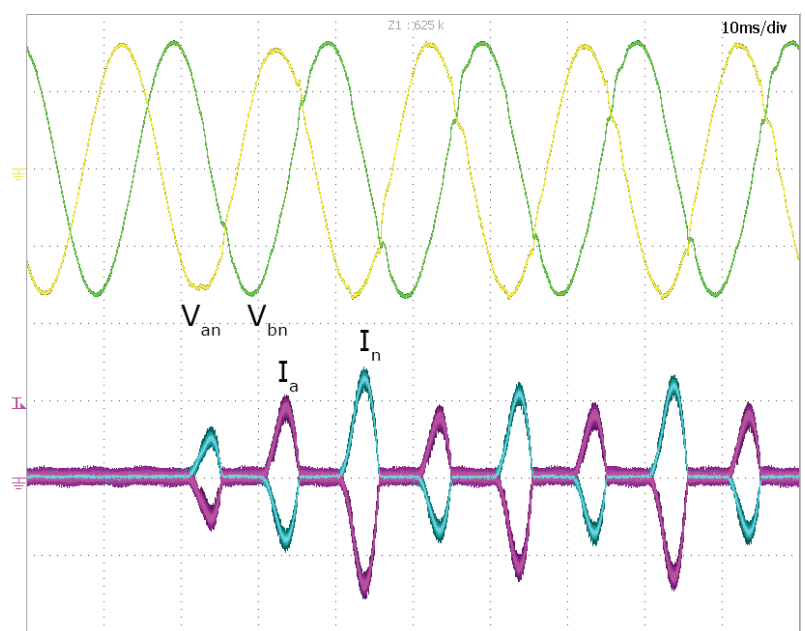

Fig. 11. Nonlinear single-phase diode rectifier load step. $(50 \mathrm{~A} / \mathrm{div}, 200 \mathrm{~V} / \mathrm{div})$

inverter," IEEE Trans. Ind. Electron., vol. 60, no. 11, pp. 4903-4912, Nov. 2013.

[10] L. Tarisciotti, P. Zanchetta, A. Watson, S. Bifaretti, and J. C. Clare, "Modulated Model Predictive Control for a Seven-Level Cascaded H-Bridge Back-to-Back Converter," IEEE Trans. Ind. Electron., vol. 61, no. 10, pp. 5375-5383, Oct. 2014.

[11] L. Tarisciotti, P. Zanchetta, A. Watson, J. C. Clare, M. Degano, and S. Bifaretti, "Modulated Model Predictive Control for a ThreePhase Active Rectifier," IEEE Trans. Ind. Appl., vol. 51, no. 2, pp. 1610-1620, Mar. 2015.

[12] R. Zhang, V. H. Prasad, D. Boroyevich, F. C. Lee, "Three Dimensional Space Vector Modulation for Four-Leg Voltage-Source Converters", IEEE Trans. Power Electron., vol. 17, no. 3, pp. 314326, Mar. 2002.

[13] V. Biagini, M. Odavic, P. Zanchetta, M. Degano, and P. Bolognesi, "Improved dead beat control of a shunt active filter for aircraft power systems," in IEEE International Symposium on Industrial Electronics (ISIE), 2010, pp. 2702-2707.

[14] S. Bifaretti, P. Zanchetta, A. J. Watson, L. Tarisciotti, and J. C. Clare, "Advanced power electronic conversion and control system for universal and flexible power management," IEEE Trans. Smart Grid, vol. 2, no. 2, pp. 231-243, 2011.

[15] L. Tarisciotti, A. J. Watson, P. Zanchetta, S. Bifaretti, J. C. Clare, and P. W. Wheeler, "An improved Dead-Beat current control for Cascaded H-Bridge active rectifier with low switching frequency," in IET International Conference onPower Electronics, Machines and Drives (PEMD), 2012, pp. 1-6.

[16] J-H. Kim, S-K. Sul, "A Carrier-Based PWM Method for ThreePhase Four-Leg Voltage Source Converters", IEEE Trans. Power Electron., vol.19, no.1, pp. 66-75, Jan. 2004.

[17] S. Bifaretti, A. Lidozzi, L. Solero and F. Crescimbini, "Modulation With Sinusoidal Third-Harmonic Injection for Active Split DC-Bus Four-Leg Inverters," in IEEE Transactions on Power Electronics, vol. 31, no. 9, pp. 6226-6236, Sept. 2016. 